\title{
Is Transforming Growth Factor- $\beta$ Signaling Activated in Human Hypertrophied Prostate Treated by 5-Alpha Reductase Inhibitor?
}

\author{
Hye Kyung Kim, ${ }^{1}$ Chen Zhao, ${ }^{2}$ Bo Ram Choi, ${ }^{1}$ Han Jung Chae, ${ }^{3}$ \\ Do Sung Kim, ${ }^{3}$ and Jong Kwan Park ${ }^{1}$ \\ ${ }^{1}$ Department of Urology of Medical School and Institute for Clinical Medicine, Chonbuk National University and Biomedical Research \\ Institute and Clinical Trial Center of Medical Device of Chonbuk National University Hospital, Jeonju 561-712, Republic of Korea \\ ${ }^{2}$ Departments of Urology, Renji Hospital, Shanghai Jiao Tong University School of Medicine, and Shanghai Institute of Andrology, \\ Shanghai 200001, China \\ ${ }^{3}$ Department of Pharmacology of Medical School and Institute for Clinical Medicine, Chonbuk National University and Biomedical \\ Research Institute and Clinical Trial Center of Medical Device of Chonbuk National University Hospital, Jeonju 561-712, \\ Republic of Korea
}

Correspondence should be addressed to Jong Kwan Park; rain@chonbuk.ac.kr

Received 6 June 2013; Revised 27 September 2013; Accepted 8 October 2013

Academic Editor: Vincent Sapin

Copyright (C) 2013 Hye Kyung Kim et al. This is an open access article distributed under the Creative Commons Attribution License, which permits unrestricted use, distribution, and reproduction in any medium, provided the original work is properly cited.

\begin{abstract}
Background and Aim. It is well known that androgen deprivation relates to penile fibrosis, so we hypothesize that long-term treatment with 5-alphareductase inhibitors (5ARIs) may increase the risk of fibrosis of prostate. Patients and Methods. Thirtytwo $\mathrm{BPH}$ patients who underwent transurethral resection of the prostate were enrolled. The patients were divided into two groups: group one, 16 patients underwent TURP who had been treated with tamsulosin for 2 years; group two, 16 patients underwent TURP who had been treated with combination of tamsulosin and dutasteride for at least 1 year. We evaluated the expressions of nNOS, iNOS, eNOS, TGF- $\beta 1$, TGF- $\beta 2$, phosphorylated-Smad2/3 (p-Smad2/3), E-cadherin, N-cadherin, and $\alpha$-smooth muscle actin in the resected prostate tissues by western blotting, and the TGF- $\beta$ concentration was determined by ELISA kit. Results. The expressions of 3 isoforms of NOS were significantly increased in group 2 except of eNOS in lateral prostate, and the expressions of TGF- $\beta 1$, TGF- $\beta 2$, and p-Smad $2 / 3$ increased about 2 -fold compared with group 1 . In group 2 , the E-cadherin expression decreased while Ncadherin expression increased significantly. Conclusions. The overexpression of nNOS may contribute to prostate smooth muscle relaxation; however, long-time treatment with $5 \mathrm{ARI}$ increases the risk of fibrosis of prostate.
\end{abstract}

\section{Introduction}

The 5-alpha reductase (5 AR) inhibitor (5 ARI) was developed to treat the patients with symptomatic benign prostatic hyperplasia (BPH) and decrease the frequency and risk of BPH-related morbidities $[1,2]$. Presently available orally administered 5 ARIs, finasteride and dutasteride, inhibit $5 \mathrm{AR}$, an enzyme that catalyzes the irreversible reduction of testosterone (T) to dihydrotestosterone (DHT), with NADPH as the hydrogen donor [3]. Dutasteride is a selective inhibitor of 5 AR type 1 ( 5 AR1) and 5 AR type 2 ( 5 AR2). Finasteride is considered mainly an inhibitor of $5 \mathrm{AR} 2$ and is approximately
50 times weaker in inhibiting 5 AR1 than 5 AR2 [4]. The development of $\mathrm{BPH}$ is an androgen-dependent process, and androgen suppression causes regression primarily of the epithelial elements of the prostate, resulting in a reduction in the size of the gland and improvement in symptoms $[5,6]$.

As we know, androgen deprivation by surgical or medical castration is associated with penile cavernosal fibrosis resulting in penile tissue atrophy, alterations in dorsal nerve structure, alterations in endothelial morphology, reductions in trabecular smooth muscle content, increases in deposition of extracellular matrix, and increases in accumulation of adipocytes in the subtunical region of the corpus cavernosum 


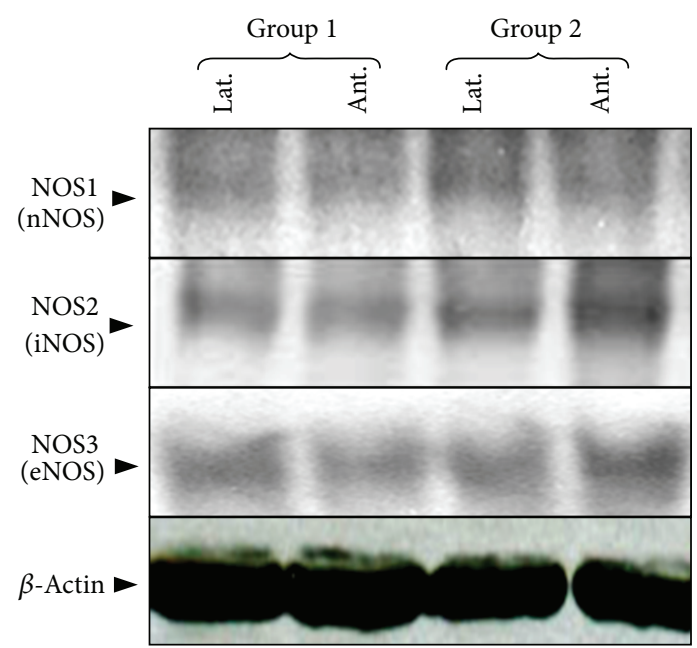

(a)

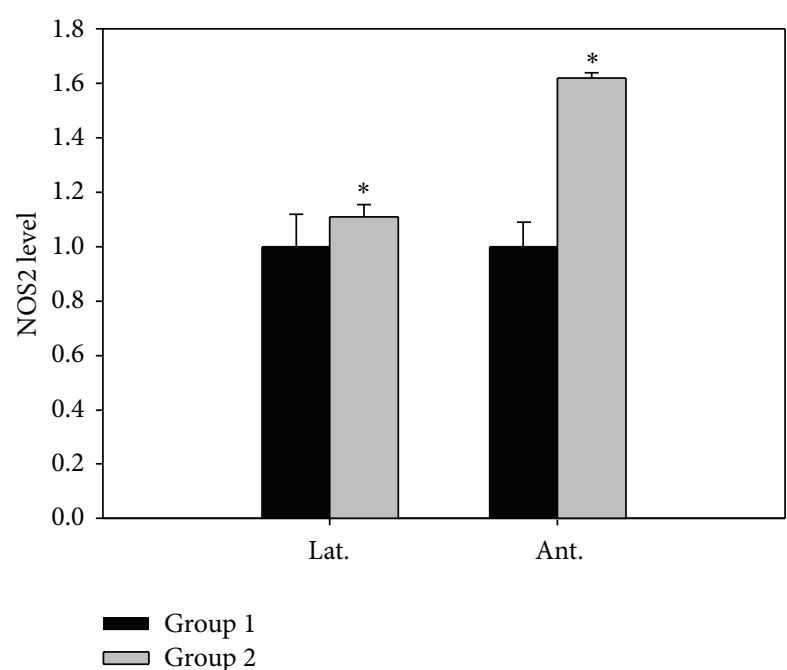

(c)

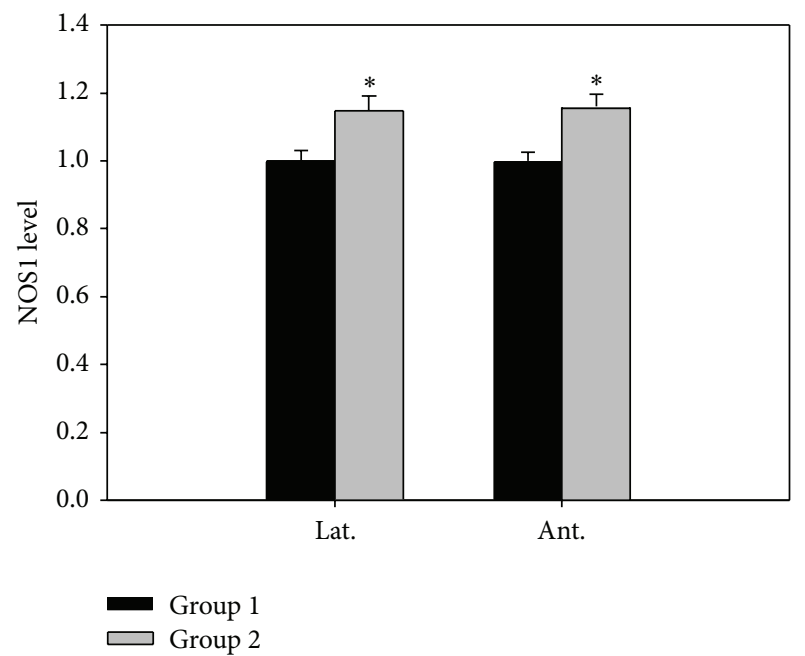

(b)

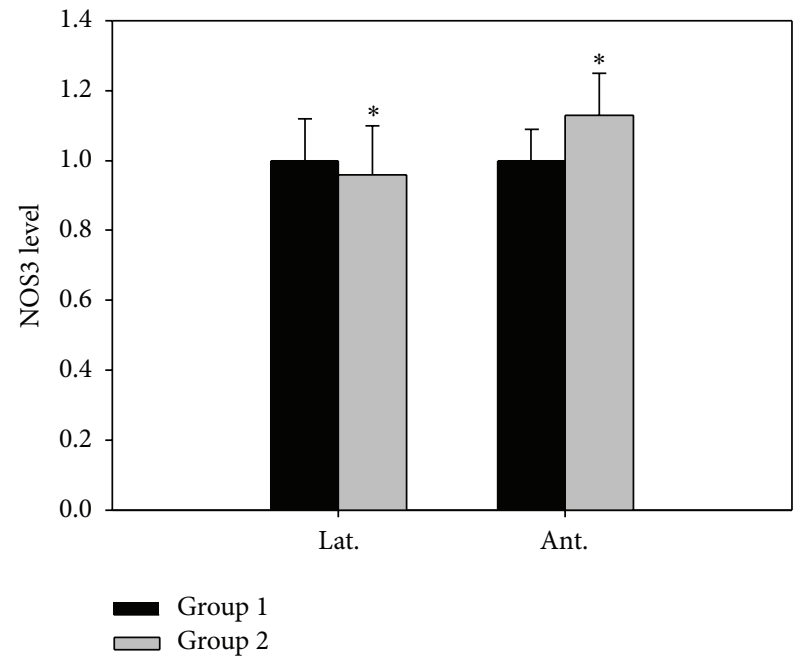

(d)

FIgURE 1: The effect of 5-alpha reductase inhibitor on expressions of nNOS, iNOS, and eNOS. nNOS: neuronal NO synthase, iNOS: inducible NO synthase, eNOS: endothelial NO synthase. Lat. means lateral portion of the prostate and Ant. means anterior wall. Each value is expressed as the mean $\pm \mathrm{SD}$ of six independent experiments. ${ }^{*} P<0.05$ versus control.

TABLE 1: Patients characteristics.

\begin{tabular}{lcc}
\hline Variants & $\begin{array}{c}\text { Group 1 } \\
(n=16)\end{array}$ & $\begin{array}{c}\text { Group 2 } \\
(n=16)\end{array}$ \\
\hline Age (years) & $68.9 \pm 7.4$ & $69.4 \pm 6.9$ \\
\hline Preoperative PSA & $3.3 \pm 1.92$ & $4.8 \pm 3.9$ \\
Total prostate volume & $45.9 \pm 18.7$ & $48.2 \pm 16.5$ \\
T-zone volume & $21.4 \pm 13.0$ & $20.3 \pm 12.1$ \\
Resection volume & $19.8 \pm 15.3$ & $18.6 \pm 16.6$ \\
\hline
\end{tabular}

PSA means prostate specific antigen. T-zone means transitional zone.

[7]. Transforming growth factor- $\beta$ (TGF- $\beta$ ) signaling pathway plays the most important role in the fibrotic process.
TGF- $\beta$ reduces collagenase production and stimulates the expression of tissue inhibitor of metalloproteinases, resulting in an overall inhibition of extracellular matrix (ECM) degradation and leading to excessive matrix accumulation $[8,9]$.

As androgen deprivation by surgical or medical castration induces cavernosal fibrosis, it may also affect the prostate tissue. In the present study, we investigated the effect of longtime treatment with 5 ARI on TGF- $\beta$ signaling pathway in the prostate of $\mathrm{BPH}$ patients.

\section{Patients and Methods}

2.1. Patients. Total $32 \mathrm{BPH}$ patients complaining of moderate-to-severe lower urinary tract symptoms (LUTS) who 


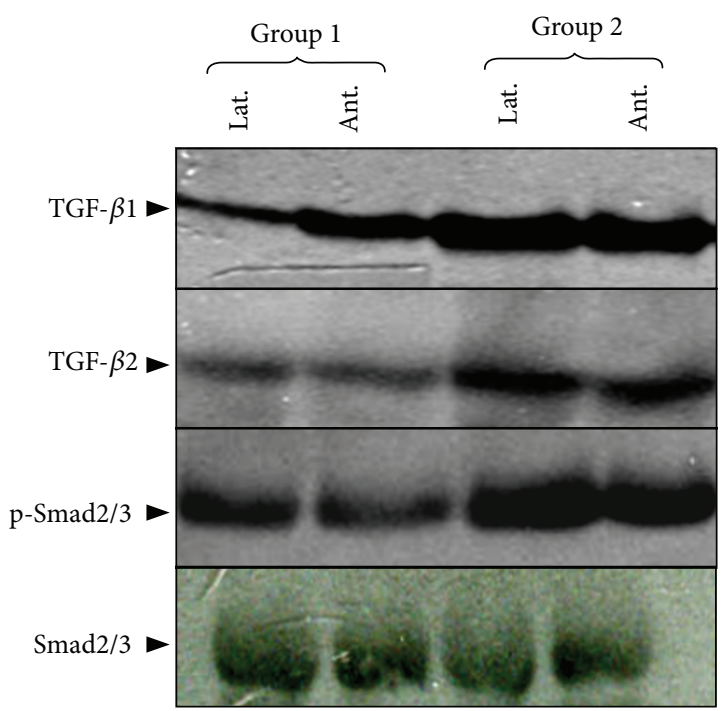

(a)

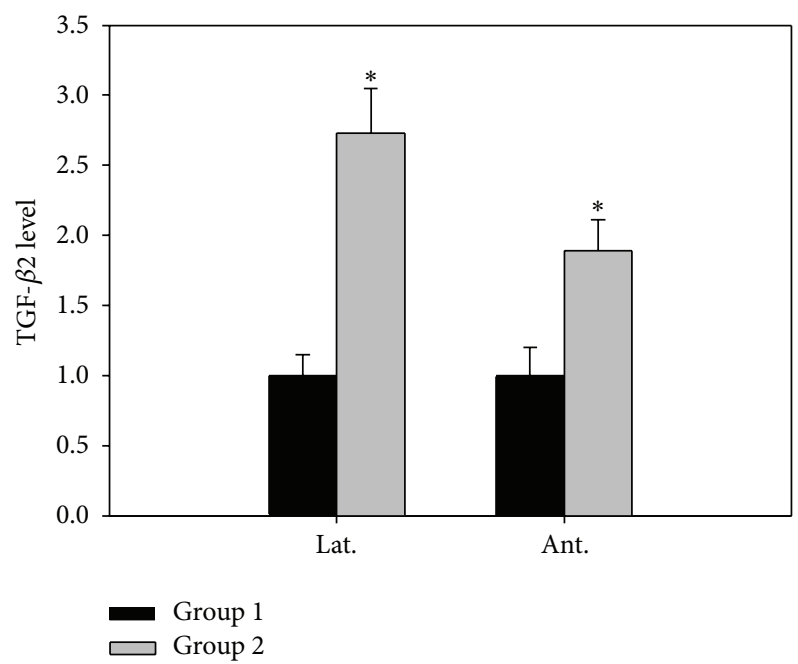

(c)

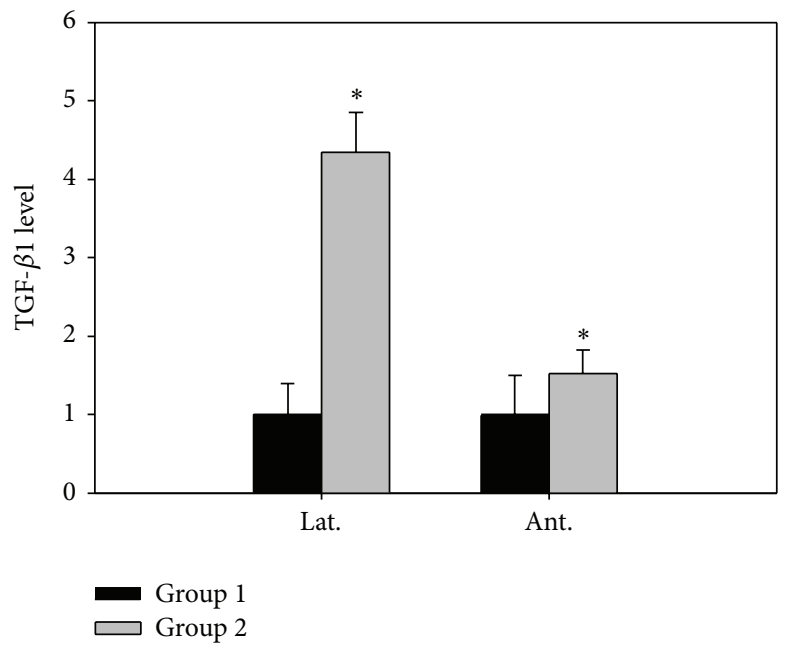

(b)

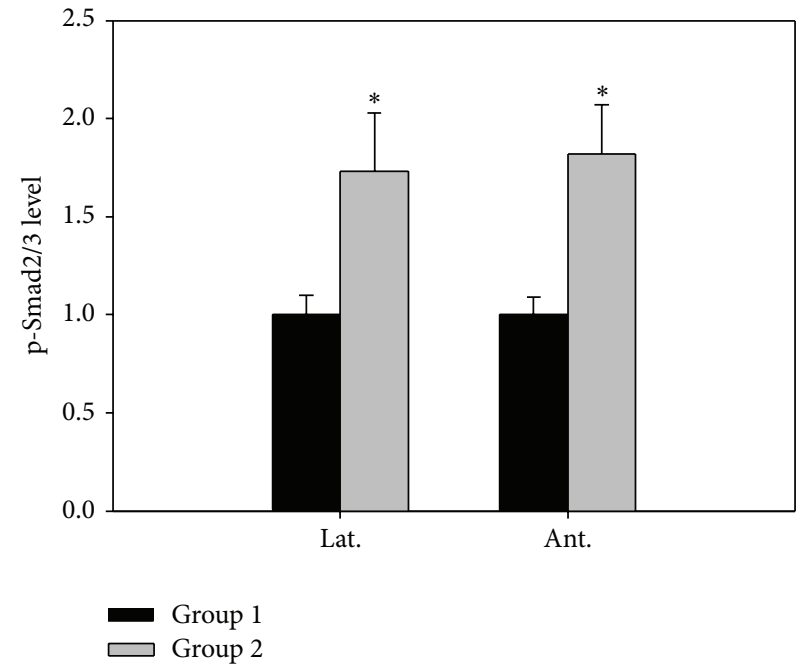

(d)

FIGURE 2: The effect of 5 -alpha reductase inhibitor on expression of TGF- $\beta 1$, TGF- $\beta 2$, and p-Smad2/3. Lat. means lateral portion of the prostate and Ant. means anterior wall. Each value is expressed as the mean $\pm \mathrm{SD}$ of six independent experiments. ${ }^{*} P<0.05$ versus control.

underwent transurethral resection of the prostate (TURP) were enrolled in the present study. The patients were divided into two groups: group 1, 16 patients underwent TURP who had been treated with alpha blocker (tamsulosin) for 2 years; group 2, the other 16 patients were treated with combination of alpha blocker (tamsulosin) and 5 ARI (dutasteride) for at least 1 year before the operation (Table 1 ).

2.2. Tissue Preparation. Approximately $1 \mathrm{~g}$ of each lateral and anterior portion of the prostate tissue resected from each patient was obtained during the TURP. The tissues were immediately frozen at $-80^{\circ} \mathrm{C}$. For western blot analysis, the removed tissues were placed in protease-inhibitor buffer containing 1\% Nonidet P-40, 50 mM HEPES, pH 7.5,
$100 \mathrm{mM} \mathrm{NaCl}, 2 \mathrm{mM}$ EDTA, $1 \mathrm{mM}$ pyrophosphate, $10 \mathrm{mM}$ sodium orthovanadate, $1 \mathrm{mM}$ phenylmethylsulfonyl fluoride, and $100 \mathrm{mM}$ sodium fluoride and were homogenized. The homogenate was centrifuged at $13,000 \mathrm{rpm}$ for $30 \mathrm{~min}$. The supernatant was collected and the volume was recorded.

2.3. Western Blotting. The samples were normalized for total protein content with a pierce BCA protein assay kit (Thermo Fisher Scientific, Rockford, IL, USA). $30 \mu$ g aliquots were suspended in an equal volume of $2 \times$ Laemmli buffer containing 2-mercaptoethanol and boiled for $5 \mathrm{~min}$ before performing SDS-PAGE. Proteins were transferred to Immobilon-P membranes (Millipore, Billerica, MA, USA), blocked with skim milk (5\%), and incubated with various primary antibodies 


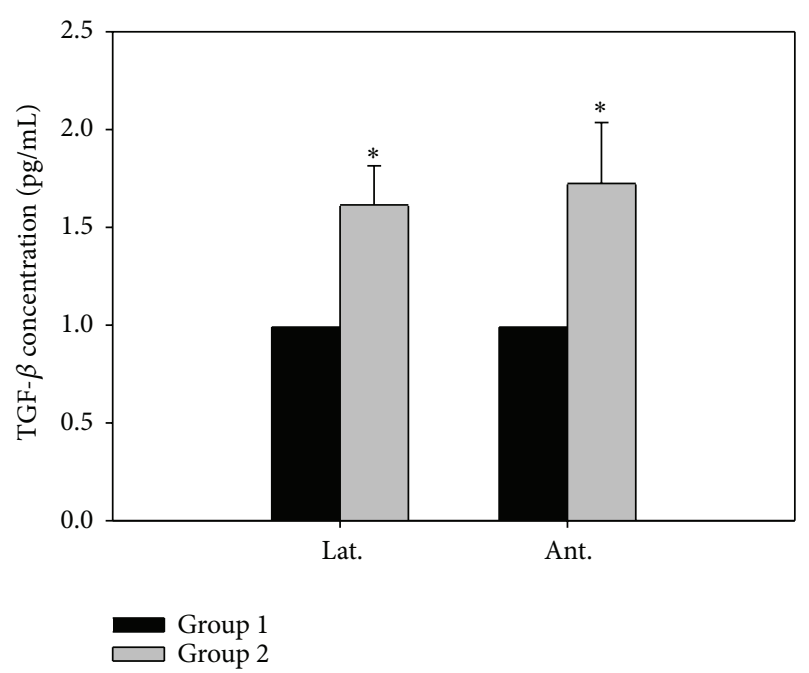

Figure 3: Human TGF- $\beta$ Immunoassay of prostate. Lat. means lateral portion of the prostate and Ant. means anterior wall. Each value is expressed as the mean $\pm \mathrm{SD}$ of six independent experiments. ${ }^{*} P<0.05$ versus control.

recognizing NOS (Santa Cruz Biotechnology, Santa Cruz, CA, USA), TGF- $\beta$ (Santa Cruz Biotechnology, Santa Cruz, CA, USA), p-Smad2/3 (Santa Cruz Biotechnology, Santa Cruz, CA, USA), Smad2/3 (Santa Cruz Biotechnology, Santa Cruz, CA, USA), E-cadherin (Cell Signaling Technology, Danvers, MA, USA), N-cadherin (Cell Signaling Technology, Danvers, MA, USA), $\alpha$-smooth muscle actin (Cell Signaling Technology, Danvers, MA, USA), and actin (Santa Cruz Biotechnology, Santa Cruz, CA, USA). Antibody detection was accomplished via horseradish peroxidase-conjugated protein A or goat anti-rabbit immunoglobulin G (Santa Cruz Biotechnology, Santa Cruz, CA, USA), a chemiluminescent substrate (Millipore, Billerica, MA, USA), and exposure to Xray film (Eastman Kodak Co., Rochester, NY, USA).

2.4. Human TGF- $\beta$ Immunoassay. The samples were normalized for total protein content with a BCA kit and tested immediately or preserved at $-80^{\circ} \mathrm{C}$. TGF- $\beta$ levels were analyzed using a commercially available ELISA (R\&D Systems, Minneapolis, MN, USA) per the manufacturer's protocol. Briefly, this assay employs the quantitative sandwich enzyme immunoassay technique. A monoclonal antibody specific for TGF- $\beta 1$ has been precoated onto a microplate. Standard, controls, and samples are pipetted into the wells and any TGF- $\beta 1$ present is bound by the immobilized antibody. After washing away any unbound substances, an enzymelinked polyclonal antibody specific for TGF- $\beta 1$ is added to the wells to sandwich the TGF- $\beta 1$ immobilized during the first incubation. Following a wash to remove any unbound antibody-enzyme reagent, a substrate solution is added to the wells and color develops in proportion to the amount of TGF$\beta 1$ bound in the initial step. The color development is stopped and the intensity of the color is measured.
2.5. Statistical Analyses. Data were presented as means \pm SD. The statistical significances of the differences were calculated by one-way ANOVA followed by Bonferroni's multiple comparison. The values were compared using Student's paired $t$ test. A $P$ value $<0.05$ was considered statistically significant.

\section{Results}

3.1. The Expression of nNOS, iNOS, and eNOS. The expressions of nNOS and iNOS were significantly increased in group 2. However, the expression of eNOS in lateral portion of prostate was decreased (Figure 1, $P<0.05$ ).

3.2. The Expression of TGF- $\beta$. Western blot of TGF- $\beta$ was shown in Figure 2. The upregulated expressions of TGF- $\beta 1$ and TGF- $\beta 2$ were observed in group 2 . The result showed that lateral portion of prostate expressed more TGF- $\beta 1$, TGF- $\beta 2$ than anterior wall. P-Smad2/3 expression was also increased in group 2, but there was no difference between the lateral portion and anterior wall (Figure 2, $P<0.05$ ).

The TGF- $\beta$ level was determined by ELISA, and the results indicated that TGF- $\beta$ was significantly increased in group 2 (Figure $3, P<0.05$ ).

3.3. The Expression of E-Cadherin and N-Cadherin. The western blotting results of $\mathrm{E}$-cadherin and $\mathrm{N}$-cadherin were shown in Figure 4. The E-cadherin level decreased and Ncadherin increased significantly in group 2. Alpha smooth muscle actin was markedly increased in group 2 and expressed more in lateral portion of the prostate.

\section{Discussion}

TGF- $\beta$ participates in the pathogenesis of multiple cardiovascular diseases, including hypertension, atherosclerosis, cardiac hypertrophy, and heart failure [10-12]. Also, it has been shown to be a regulator of stromal proliferation and differentiation in the prostate [13]. It is well known that androgen plays an important role in the pathogenesis of $\mathrm{BPH}$. The action of androgen is mediated through actions of a host of soluble growth factors, among which TGF- $\beta$ is the most versatile in its ability to regulate proliferation, growth arrest, differentiation, and apoptosis of prostatic stromal cells [14]. It has been demonstrated that the effect of $5 \mathrm{ARI}$ on $\mathrm{BPH}$ was associated with suppression of the insulin like growth factor 1 gene and with an increase in TGF$\beta$ gene expression [15]. TGF- $\beta$ predominantly transmits the signals through cytoplasmic proteins called Smads, which translocates into the cell nucleus acting as transcription factors. Eight different members of the Smad family have been identified in mammals, in which Smad2 and Smad3 are specific mediators of TGF- $\beta$ /activin pathways $[10,11]$. In this study, the results showed that long-term treatment with 5 ARI significantly increased the expression of TGF- $\beta 1$, TGF- $\beta 2$, and $\mathrm{p}$-Samd $2 / 3$ compared with the control group, suggesting 5 ARI-induced cell death was regulated by TGF- $\beta$-Smad pathway. Decreased expression of E-cadherin accompanied by increased expression of $\mathrm{N}$-cadherin resulted in a loss of 


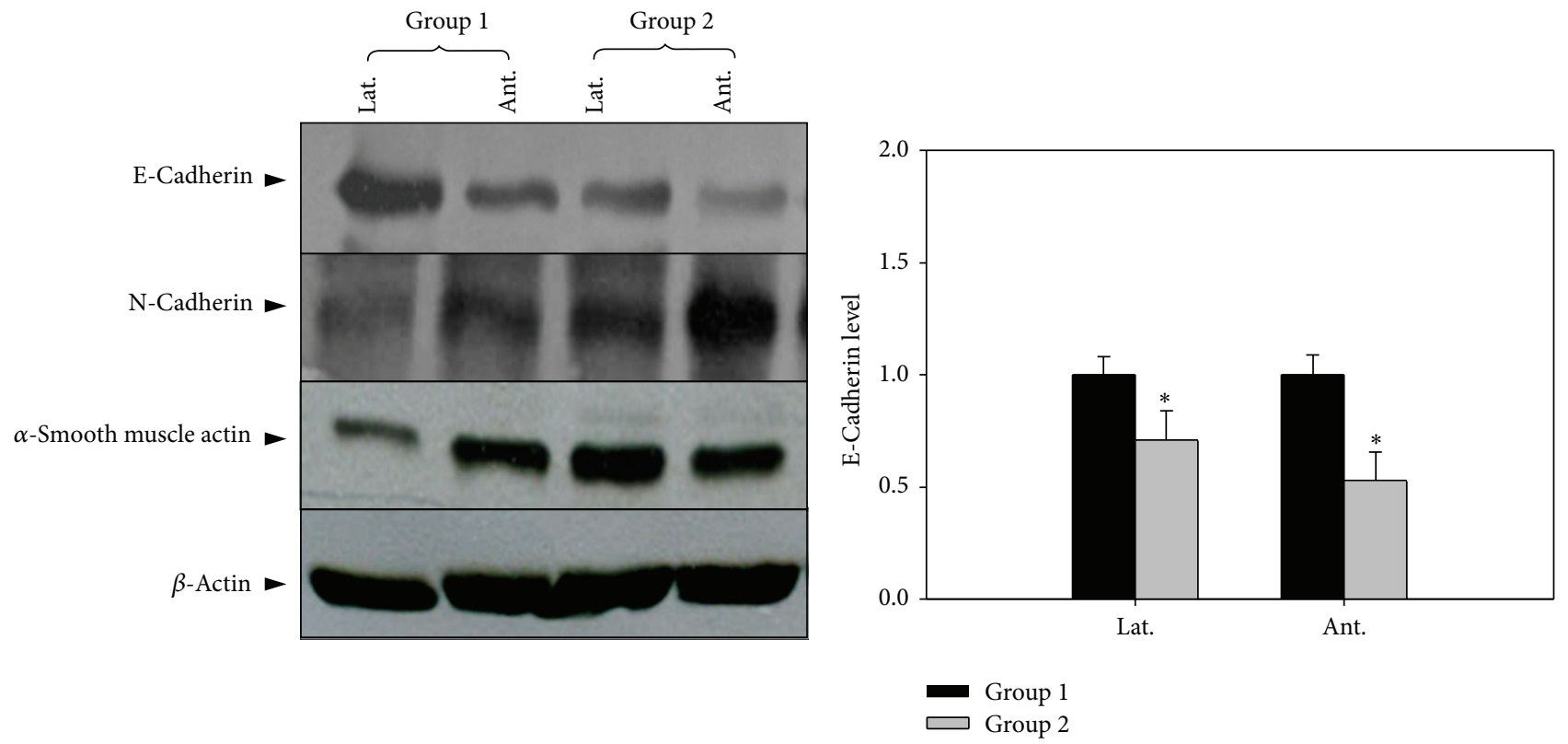

(a)
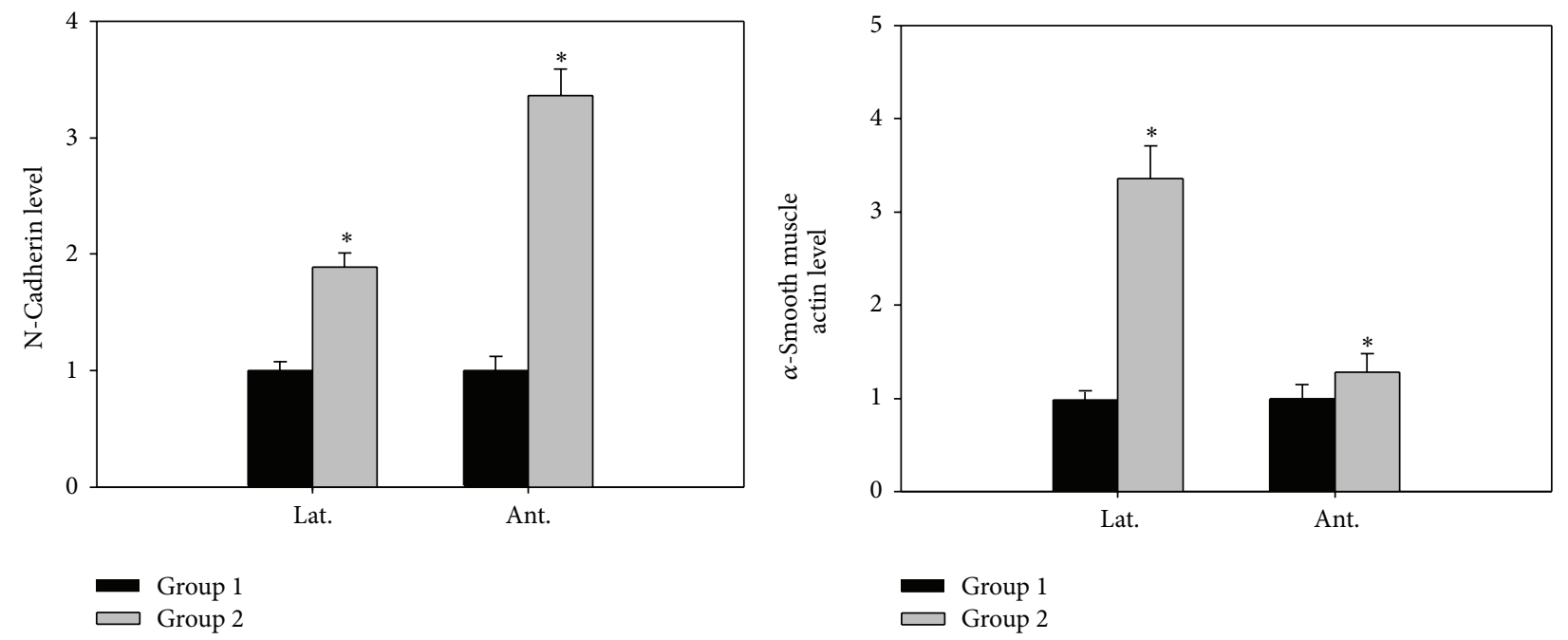

(c)

(d)

FIgURE 4: The effect of 5-alpha reductase inhibitor on expression of E, N-cadherin (Fibrosis). Lat. means lateral portion of the prostate and Ant. means anterior wall. Each value is expressed as the mean $\pm \mathrm{SD}$ of six independent experiments. ${ }^{*} P<0.05$ versus control.

epithelial characteristics and indicated that the epithelial cell underwent epithelial to mesenchymal transition (EMT).

TGF- $\beta$-Smad pathway is very important stream also involved in fibrotic process. In vascular smooth muscle cells, endothelial cells, and fibroblasts, TGF- $\beta 1$ increases the synthesis of ECM proteins, such as fibronectin, collagens, and activator inhibitor-1 (PAI-1), even at low concentrations $[8,9]$. TGF- $\beta$ induces expression of fibronectin which is required for enhancement of $\alpha$-smooth muscle actin and collagen type I expression [8]. PAI-1 is a serpin class protease inhibitor, important in tissue remodeling by modulating thrombosis, inflammation, migration, and ECM.
TGF- $\beta$ reduces collagenase production and stimulates the expression of tissue inhibitor of metalloproteinases (TIMP), resulting in an overall inhibition of ECM degradation and leading to excessive matrix accumulation $[8,9]$. The mechanisms involved in TGF- $\beta$ mediated vascular fibrosis are complex, including activation of Smad proteins, protein kinases, production of mediators, and crosstalk between pathways. TGF- $\beta$ also acts as a mediator of vascular fibrosis induced by several agents involved in cardiovascular diseases, including mechanical stress, angiotensin II, high glucose, and advanced glycation products [16-18]. In Peyronie's disease, the fibrosis is characterized by an increase in collagen over 
the intracellular compartment and is associated with the production of profibrotic factors, such as TGF- $\beta 1$, PAI-1, and reactive oxygen species during oxidative stress [19-21]. This fibrosis is accompanied by the induction of iNOS, which acts as an endogenous antifibrotic mechanism in response to the profibrotic processes $[19,22]$.

The presence of NOS has been demonstrated in the human prostate that the eNOS is related to the maintenance of local vascular perfusion, whereas the nNOS is mainly involved in the control of smooth muscle tone and glandular function, including proliferation of epithelial and subepithelial cells $[23,24]$. Until today, the inducible form of NOS, the iNOS, has not been found in normal prostate tissue; however, there are hints that the enzyme is expressed in hyperplastic and malignant tissue $[25,26]$. The reduction in glandular tissue by $5 \mathrm{ARI}$ is achieved by the induction of apoptosis, which is histologically manifested by ductal atrophy. Inhibition also diminishes the number of blood vessels in the prostate because of a reduction in vascularderived endothelial growth factor which downregulates the eNOS expression in lateral portion of prostate [27].

\section{Conclusions}

The overexpression of nNOS may contribute to prostate smooth muscle relaxation and improve the symptoms; however, long-time treatment with $5 \mathrm{ARI}$ increases the risk of fibrosis by the TGF- $\beta$-p-Smad signaling pathway.

\section{What is Known?}

(1) The 5 ARIs have been successfully used for treatment of BPH by inhibiting the conversion of T to DHT, resulting in a reduction in the size of the gland and improvement in symptoms.

(2) Androgen deprivation by surgical or medical castration is associated with penile cavernosal fibrosis.

\section{What is New?}

(1) Androgen deprivation induced by long-term treatment with $5 \mathrm{ARI}$ increases the risk of fibrosis via the TGF- $\beta$-p-Smad signaling pathway.

(2) The upregulated nNOS expression may contribute to prostate smooth muscle relaxation and improve the symptoms.

\section{Conflict of Interests}

The authors do not have conflict of interests to declare and also do not have anything to declare about Santa Cruz Biotechnology, Thermo Fisher Scientific, Cell Signaling Technology, and Eastman Kodak Co.

\section{Authors' Contribution}

Hye Kyung Kim, Chen Zhao, Bo Ram Choi, Han Jung Chae, Do Sung Kim, and Jong Kwan Park were involved in the laboratory procedures, data collection, and analysis. Hye Kyung Kim and Jong Kwan Park were involved in the preparation of the paper and the review of the paper.

\section{Acknowledgment}

This study was supported by Grants from the Korea Healthcare Technology R\&D Project, Ministry for Health, Welfare \& Family Affairs, Republic of Korea (HI13C0104).

\section{References}

[1] J. D. McConnell, R. Bruskewitz, P. Walsh et al., "The effect of finasteride on the risk of acute urinary retention and the need for surgical treatment among men with benign prostatic hyperplasia," The New England Journal of Medicine, vol. 338, no. 9, pp. 557-563, 1998.

[2] C. G. Roehrborn, P. Boyle, J. C. Nickel, K. Hoefner, and G. Andriole, "Efficacy and safety of a dual inhibitor of 5-alphareductase types 1 and 2 (dutasteride) in men with benign prostatic hyperplasia," Urology, vol. 60, no. 3, pp. 434-441, 2002.

[3] D. W. Russell and J. D. Wilson, "Steroid $5 \alpha$-reductase: two genes/two enzymes," Annual Review of Biochemistry, vol. 63, pp. 25-61, 1994.

[4] S. Aggarwal, S. Thareja, A. Verma, T. R. Bhardwaj, and M. Kumar, "An overview on $5 \alpha$-reductase inhibitors," Steroids, vol. 75, no. 2, pp. 109-153, 2010.

[5] D. S. Coffey and P. C. Walsh, "Clinical and experimental studies of benign prostatic hyperplasia," Urologic Clinics of North America, vol. 17, no. 3, pp. 461-475, 1990.

[6] C. A. Peters and P. C. Walsh, "The effect of nafarelin, acetate, a luteinizing-hormone-releasing hormone agonist, on benign prostatic hyperplasia," The New England Journal of Medicine, vol. 317, no. 10, pp. 599-604, 1987.

[7] A. I. El-Sakka and A. A. Yassin, "Review: amelioration of penile fibrosis: myth or reality," Journal of Andrology, vol. 31, no. 4, pp. 324-335, 2010.

[8] A. Leask and D. J. Abraham, "TGF- $\beta$ signaling and the fibrotic response," The FASEB Journal, vol. 18, no. 7, pp. 816-827, 2004.

[9] F. Verrecchia and A. Mauviel, "Transforming growth factor$\beta$ signaling through the Smad pathway: role in extracellular matrix gene expression and regulation," Journal of Investigative Dermatology, vol. 118, no. 2, pp. 211-215, 2002.

[10] J. Massagué, J. Seoane, and D. Wotton, "Smad transcription factors," Genes and Development, vol. 19, no. 23, pp. 2783-2810, 2005.

[11] D. Javelaud and A. Mauviel, "Mammalian transforming growth factor- $\beta$ s: smad signaling and physio-pathological roles," International Journal of Biochemistry and Cell Biology, vol. 36, no. 7, pp. 1161-1165, 2004.

[12] A. Moustakas, K. Pardali, A. Gaal, and C.-H. Heldin, "Mechanisms of TGF- $\beta$ signaling in regulation of cell growth and differentiation," Immunology Letters, vol. 82, no. 1-2, pp. 85-91, 2002.

[13] X. Huang and C. Lee, "Regulation of stromal proliferation, growth arrest, differentiation and apoptosis in benign prostatic hyperplasia by TGF- $\beta$," Frontiers in Bioscience, vol. 8, pp. s740s749, 2003.

[14] T. L. Timme, L. D. Truong, K. M. Slawin, D. Kadmon, S. H. P. Sang Hee Park, and T. C. Thompson, "Mesenchymal-epithelial 
interactions and transforming growth factor- $\beta 1$ expression during normal and abnormal prostatic growth," Microscopy Research and Technique, vol. 30, no. 4, pp. 333-341, 1995.

[15] S.-F. Wu, H.-Z. Sun, X.-D. Qi, and Z.-H. Tu, "Effect of epristeride on the expression of IGF-1 and TGF- $\beta$ receptors in androgen-induced castrated rat prostate," Experimental Biology and Medicine, vol. 226, no. 10, pp. 954-960, 2001.

[16] M. Ruiz-Ortega, M. Ruperez, V. Esteban, and J. Egido, "Molecular mechanisms of angiotensin II-induced vascular injury," Current Hypertension Reports, vol. 5, no. 1, pp. 73-79, 2003.

[17] J. H. Li, X. R. Huang, H.-J. Zhu, R. Johnson, and H. Y. Lan, "Role of TGF- $\beta$ signaling in extracellular matrix production under high glucose conditions," Kidney International, vol. 63, no. 6, pp. 2010-2019, 2003.

[18] J. H. Li, X. R. Huang, H.-J. Zhu et al., "Advanced glycation end products activate Smad signaling via TGF-beta-dependent and independent mechanisms: implications for diabetic renal and vascular disease," The FASEB Journal, vol. 18, no. 1, pp. 176-178, 2004.

[19] N. F. Gonzalez-Cadavid and J. Rajfer, "Mechanisms of disease: new insights into the cellular and molecular pathology of Peyronie's disease," Nature Clinical Practice Urology, vol. 2, no. 6, pp. 291-297, 2005.

[20] A. I. El-Sakka, H. M. Hassoba, R. J. Pillarisetty, R. Dahiya, and T. F. Lue, "Peyronie's disease is associated with an increase in transforming growth factor- $\beta$ protein expression," Journal of Urology, vol. 158, no. 4, pp. 1391-1394, 1997.

[21] T. J. Bivalacqua, E. K. Diner, T. E. Novak et al., "A rat model of Peyronie's disease associated with a decrease in erectile activity and an increase in inducible nitric oxide synthase protein expression," Journal of Urology, vol. 163, no. 6, pp. 1992-1998, 2000.

[22] H. H. Davila, T. R. Magee, D. Vernet, J. Rajfer, and N. F. Gonzalez-Cadavid, "Gene transfer of inducible nitric oxide synthase complementary DNA regresses the fibrotic plaque in an animal model of Peyronie's disease," Biology of Reproduction, vol. 71, no. 5, pp. 1568-1577, 2004.

[23] A. L. Burnett, M. P. Maguire, S. L. Chamness et al., "Characterization and localization of nitric oxide synthase in the human prostate," Urology, vol. 45, no. 3, pp. 435-439, 1995.

[24] R. Gradini, M. Realacci, A. Ginepri et al., "Nitric oxide synthases in normal and benign hyperplastic human prostate: immunohistochemistry and molecular biology," The Journal of Pathology, vol. 189, pp. 224-229, 1999.

[25] T. Klotz, W. Bloch, C. Volberg, U. Engelmann, and K. Addicks, "Selective expression of inducible nitric oxide synthase in human prostate carcinoma," Cancer, vol. 82, pp. 1897-1903, 1998.

[26] S. Baltaci, D. Orhan, Ç. Gögüs, K. Türkölmez, Ö. Tulunay, and O. Gögüs, "Inducible nitric oxide synthase expression in benign prostatic hyperplasia, low- and high-grade prostatic intraepithelial neoplasia and prostatic carcinoma," BJU International, vol. 88, no. 1, pp. 100-103, 2001.

[27] L. S. Marks, A. W. Partin, F. J. Dorey et al., "Long-term effects of finasteride on prostate tissue composition," Urology, vol. 53, no. 3, pp. 574-580, 1999. 


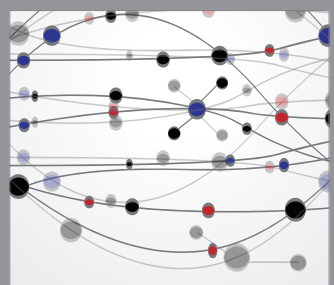

The Scientific World Journal
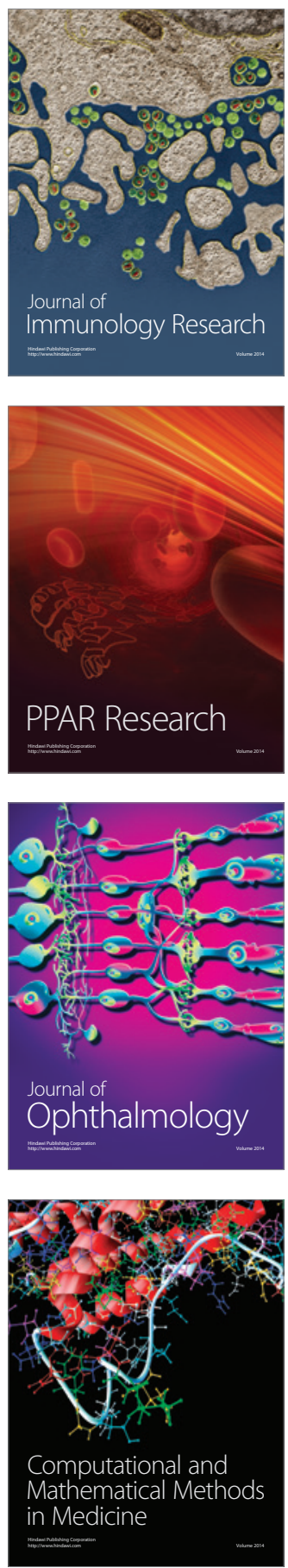

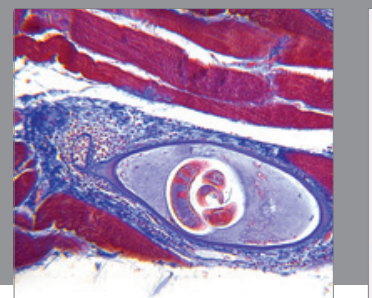

Gastroenterology

Research and Practice
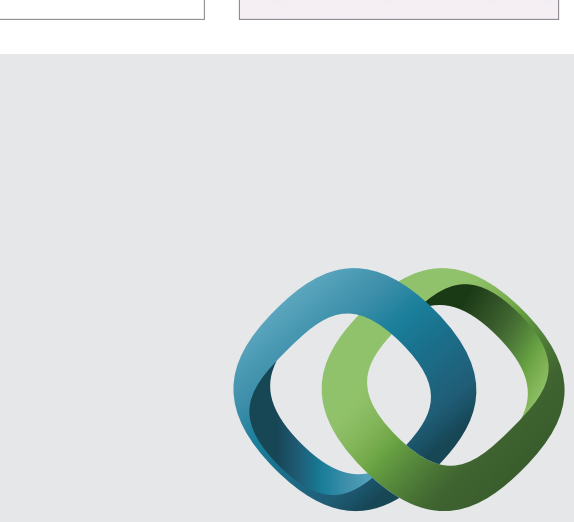

\section{Hindawi}

Submit your manuscripts at

http://www.hindawi.com
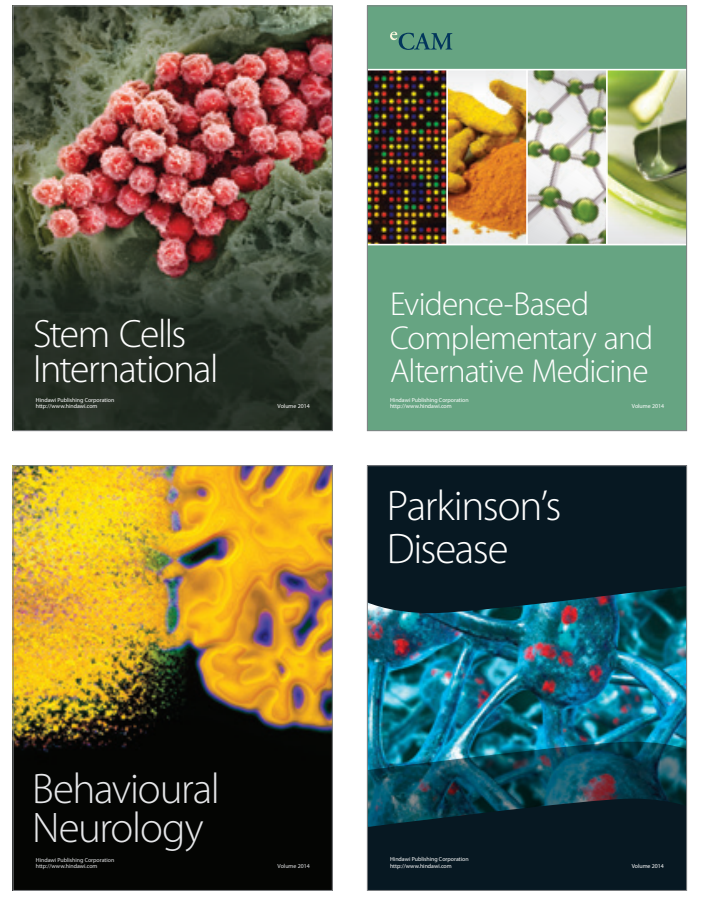
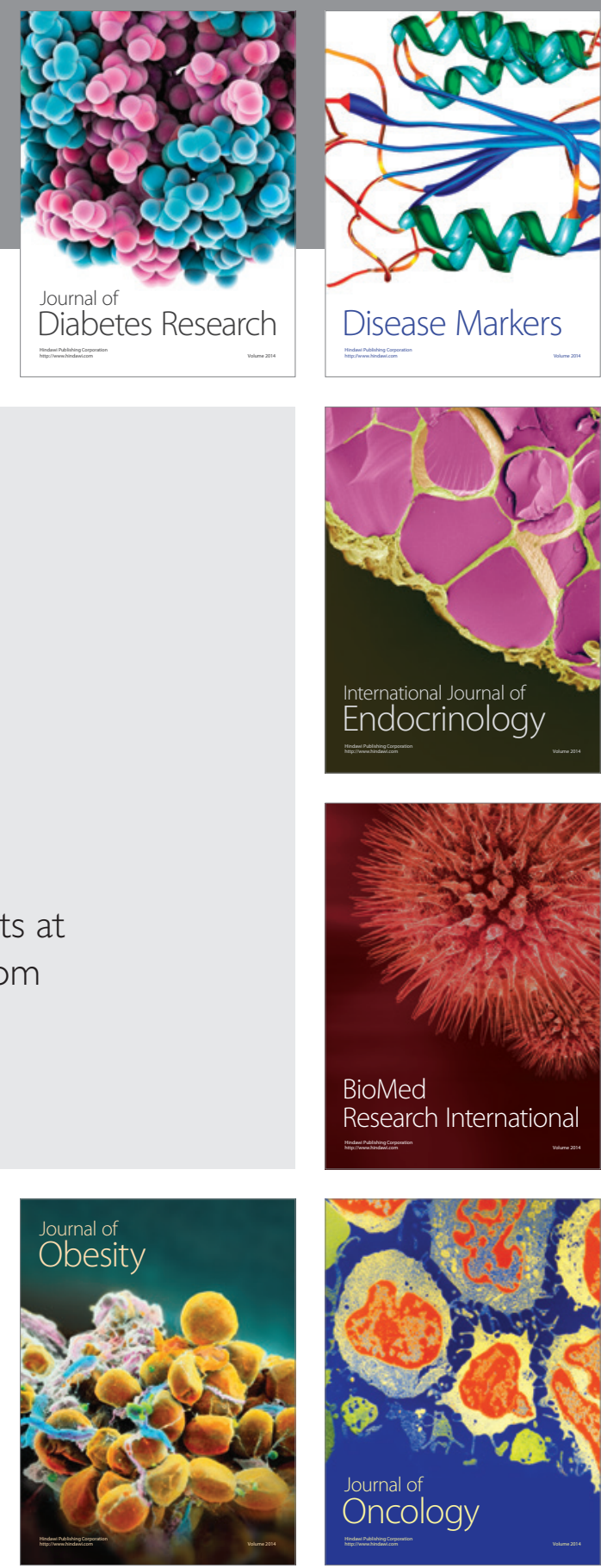

Disease Markers
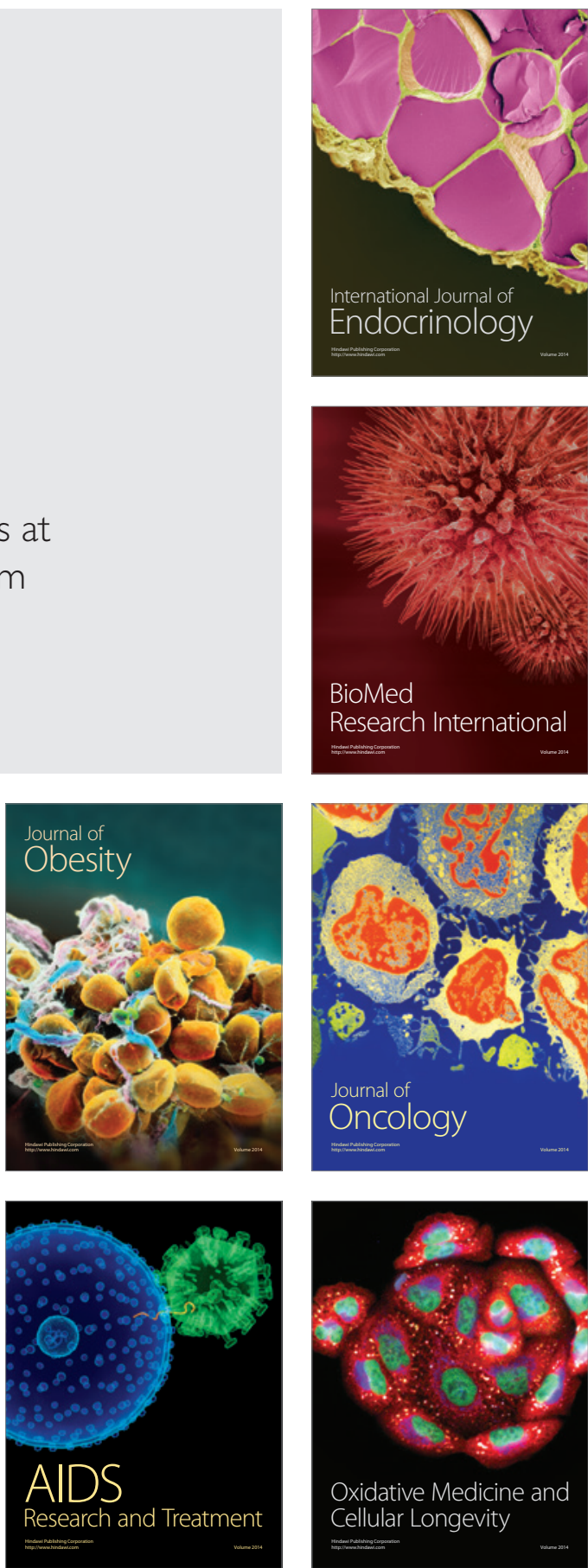